\title{
Relationship between Molar Incisor Hypomineralization and dental caries at eight-year-old children
}

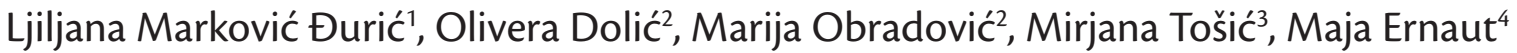 \\ 'Primary Health Care Center, Kneževo, Bosnia and Herzegovina; \\ 'University of Banja Luka, Faculty of Medicine, Banja Luka, Bosnia and Herzegovina; \\ ${ }^{3}$ Primary Health Care Center, Gradiška, Bosnia and Herzegovina; \\ ${ }^{4}$ Primary Health Care Center, Srbac, Bosnia and Herzegovina
}

\begin{abstract}
SUMMARY
Introduction The aim of the present study was to determine the relationship between Molar Incisor Hypomineralization $(\mathrm{MIH})$ and caries in school children from Banja Luka region, Republic of Srpska.

Materials and methods One calibrated dentist evaluated a sample of 529 schoolchildren, eight years old, according to the European Academy of Pediatric Dentistry (EAPD) criteria on MIH presence. Dental caries was assessed using the DMFT (Decayed, Missing, Filled Teeth) criteria.

Results DMFT/dmft was significantly higher in children with MIH than without $M I H(p<0.001)$. In the MIH group of children, high values of caries indices (\%DMFT/\%dmft and mean DMFT/dmft) were found.

Conclusion Significant association between MIH and dental caries in eight-year-olds was found.

Keywords: molar incisor hypomineralization; dental caries; children
\end{abstract}

\section{INTRODUCTION}

Oral health is an essential part of the overall health. Regardless the knowledge of dental caries causes, it is still the most widespread disease of civilization and global problem. During the past decades in many developed countries it has been noticed a decline in caries prevalence of children and adolescents. Opposite to reduced prevalence of dental caries, developmental anomalies of enamel are increasingly drawing attention in clinical practice and becoming more prominent public health problem [1].

An increased frequency of structural anomalies of enamel has been noticed in the past years mainly affecting first permanent molars and incisors. For better understanding of these changes and their impact on overall oral health, Karin Werheijm et al. (2001) suggested a single term - Molar Incisor Hypomineralization (MIH), which was accepted at the meeting of the European Academy of Paediatric Dentistry in Athens in 2003 [2]. This condition is characterized by hypomineralization of systemic origin that affects one or more first permanent molars in association with defects of permanent incisors [3].

Beside clinical implications of MIH (thermal, chemical and mechanical hypersensitivity, lack of esthetics - appearance of white, yellow or brown opacity), hypomineralized changes are strong predictors of dental caries. Affected teeth, in particular first permanent molars, are susceptible to dental caries, not only because of enamel porosity, but also increased teeth sensitivity that make effective oral hygiene difficult [4]. Furthermore, low sali- vary flow rates and low $\mathrm{pH}$ have been observed in $\mathrm{MIH}$ children, as another factor that could possibly contribute to higher caries risk [5]. In more severe cases, hypersensitivity may be increased to the level that is hard to achieve efficient dental analgesia during preparation. What is even worse is that children with this type of defect require extensive and often repeated restorative treatments. Conservative treatments of these teeth are challenging for both, a patient and a dentist. In many cases, dental fear and anxiety is present which complicate treatment additionally $[6,7]$. For these reasons, monitored tooth eruption, adoption of timely and accurate diagnosis of $\mathrm{MIH}$ is crucial for proper selection of therapeutic procedures and prevention of further damage.

The aim of the present study was to determine the prevalence of dental caries in children with $\mathrm{MIH}$, and relationship between MIH and caries development in permanent and primary teeth.

\section{MATERIALS AND METHODS}

A cross-sectional study was conducted in Banja Luka region, where 540 school children, aged 8 years were screened for MIH and decayed, missing and filled teeth (DMFT). Study was conducted between September 2015 and March 2016. Age of eight was chosen because first permanent molars and incisors erupted recently, so caries prevalence should still be low and therefore lower possibility for caries lesion to mask hypomineralisation [2]. 
The Ethical Committee of the Institute for Clinical Dentistry of Banja Luka and the Ethical Committee of Public Health Centre, Banja Luka approved the study.

Two stage sampling procedure was adopted for sample selection. In the first stage, 9 schools of all 30 were selected by random sampling. In the second stage, children were recruited, from the selected schools, by proportionate stratified random sampling. Children without parental informed consent signed and children with fixed orthodontic appliances were excluded from the study. A written informed consent was obtained from parents before clinical examination of their children.

One calibrated dentist, using a dental mirror and a probe, examined children in dental chair under artificial light. If necessary, cotton rolls were used to remove any residual debris. The criteria proposed by the European Academy of Pediatric Dentistry (EAPD) were used for the diagnosis of $\mathrm{MIH}$, which included the presence of demarcated opacities, post-eruptive enamel breakdown, atypical restorations and extraction due to $\mathrm{MIH}$ of at least one first permanent molar [3]. Tooth lesions that were less than $1 \mathrm{~mm}$ in diameter were not included in the study, the opacities that were only observed on the incisors without the involvement of the molars were not diagnosed as $\mathrm{MIH}$. The cases of excessive caries lesions haloed with opacities were diagnosed as MIH.

Dental caries experience was recorded using the WHO (World Health Organization) criteria for diagnosis of decayed (D), missing (M) and filled (F) teeth (DMFT/dmft Index) [8]. The caries prevalence was expressed in statistical coefficients: \%DMFT/\%dmft index and mean DMFT/ $\mathrm{dmft}$ index. The examination of dental caries included all permanent and primary teeth. According to clinical features of $\mathrm{MIH}$, required treatment needs were presented in five groups: no treatment required, one-surface filling, two- or multi-surface filling, endodontic treatment and tooth extraction.
The data were analyzed using the IBM SPSS Statistics 21.0. A comparison between groups was carried out using the Pearson's correlations and Mann-Whitney U-test. For all tests the $P$-value of 0.05 or less was considered statistically significant.

\section{RESULTS}

Out of 540 children, nine did not have signed permission by their parents and therefore were not examined. Two children had partially erupted or unerupted all four permanent molars and were excluded as well. Finally, a total of 529 (97.96\%) children (254 boys and 275 girls) were included in the study. Analysis of results about the prevalence of dental caries showed DMFT/dmft in permanent and primary teeth was significantly higher in children with MIH than without MIH $(\mathrm{p}<0.001)$ (Table 1$)$. In the examined groups, high values of analyzed parameters for caries prevalence \%DMFT/dmft and mean DMFT/dmft were found, but both significantly higher in the group with MIH (Table 2). Table 3 shows evaluation of the need for dental treatment of teeth affected by hypomineralization changes.

\section{DISCUSSION}

Our study evaluated the relationship between MIH and dental caries in school children of Banja Luka region, Republic of Srpska. Increased porosity of tooth structure and consequently reduced mechanical resistance of hypomineralized changes pose great risk for dental caries, even in populations with low caries prevalence.

Statistically significant correlation between DMFT $(1.41 \pm 1.62)$ and hypomineralized changes was found. This finding is consistent with the research of most au-

Table 1. Relation of DMFT/dmft median in $\mathrm{MIH}$ and non $\mathrm{MIH}$ - group

Tabela 1. Odnos medijane KEP/kep-a između grupa sa MIH promenama i bez MIH promena

\begin{tabular}{|c|c|c|c|c|c|}
\hline \multirow{2}{*}{$\begin{array}{l}\text { Compared groups } \\
\text { Komparirane grupe }\end{array}$} & \multicolumn{2}{|c|}{$\begin{array}{c}\text { DMFT } \\
\text { KEPP }\end{array}$} & \multicolumn{2}{|c|}{$\begin{array}{l}\text { dmft } \\
\text { kep }\end{array}$} & \multirow{2}{*}{$\begin{array}{c}\text { p-value } \\
\text { p-vrednost }\end{array}$} \\
\hline & $\begin{array}{l}\text { SD } \\
\text { SD }\end{array}$ & $\begin{array}{l}\text { Median } \\
\text { Medijana }\end{array}$ & $\begin{array}{l}\text { SD } \\
\text { SD }\end{array}$ & $\begin{array}{l}\text { Median } \\
\text { Medijana }\end{array}$ & \\
\hline $\begin{array}{l}\text { MIH group } \\
\text { Grupa sa } \mathrm{MIH} \text { promenama }\end{array}$ & $2.43 \pm 1.70$ & 2.0 & $7.40 \pm 3.08$ & 8.0 & \multirow{3}{*}{$\mathrm{p}<0.001$} \\
\hline $\begin{array}{l}\text { Non-MIH group } \\
\text { Grupa bez MIH promena }\end{array}$ & $1.23 \pm 1.54$ & 0.0 & $5.52 \pm 3.47$ & 6.0 & \\
\hline $\begin{array}{l}\text { Total } \\
\text { Ukupno }\end{array}$ & $1.41 \pm 1.62$ & 1.0 & $5.80 \pm 3.48$ & 6.0 & \\
\hline
\end{tabular}

Table 2. Relation of \%DMFT/dmft and mean DMFT/dmft in MIH and non-MIH group

Tabela 2. Odnos KIO i KIP indeksa u grupama sa MIH promenama i bez MIH promena

\begin{tabular}{|c|c|c|c|c|}
\hline \multirow{2}{*}{$\begin{array}{l}\text { Compared groups } \\
\text { Komparirane grupe }\end{array}$} & \multirow{2}{*}{$\begin{array}{c}\text { \%DMFT/dmft } \\
\text { Karijes indeks osoba (KIO) }\end{array}$} & \multicolumn{2}{|c|}{$\begin{array}{c}\text { Mean DMFT/dmft } \\
\text { Karijes indeks prosek }\end{array}$} & \multirow{2}{*}{$\begin{array}{c}\text { p-value } \\
\text { p-vrednos }\end{array}$} \\
\hline & & $\begin{array}{l}\text { Permanent teeth } \\
\text { Stalni zubi }\end{array}$ & $\begin{array}{l}\text { Primary teeth } \\
\text { Mlečni zubi }\end{array}$ & \\
\hline $\begin{array}{l}\text { MIH group } \\
\text { Grupa sa MIH promenama }\end{array}$ & $80 \%$ & 2.3 & 7.4 & \multirow{2}{*}{$\mathrm{p}<0.001$} \\
\hline $\begin{array}{l}\text { Non-MIH group } \\
\text { Grupa bez MIH promena }\end{array}$ & $50.3 \%$ & 1.2 & 5.5 & \\
\hline
\end{tabular}


Table 3. Distribution of MIH by treatment need

Tabela 3. Distribucija zuba sa MIH-om prema potrebi za tretmanom

\begin{tabular}{|l|c|c|}
\hline \multirow{2}{*}{$\begin{array}{l}\text { TREATMENT } \\
\text { TRETMAN }\end{array}$} & \multicolumn{2}{|c|}{$\begin{array}{c}\text { TEETH WITH MIH } \\
\text { ZUBI SA MIH-om }\end{array}$} \\
\cline { 2 - 3 } & N & $\%$ \\
\hline $\begin{array}{l}\text { No treatment } \\
\text { Nije potreban }\end{array}$ & 230 & $72.33 \%$ \\
\hline $\begin{array}{l}\text { One surface restoration } \\
\text { Jednopovršinski ispun }\end{array}$ & 46 & $14.47 \%$ \\
\hline $\begin{array}{l}\text { Two or more surfaces restoration } \\
\text { Dvopovršinski ili višepovršinski ispun }\end{array}$ & 17 & $5.34 \%$ \\
\hline $\begin{array}{l}\text { Endodontic treatment } \\
\text { Endodontski tretman }\end{array}$ & 5 & $1.57 \%$ \\
\hline $\begin{array}{l}\text { Tooth extraction } \\
\text { Ekstrakcija zuba }\end{array}$ & 20 & $6.29 \%$ \\
\hline $\begin{array}{l}\text { TOTAL } \\
\text { UKUPNO }\end{array}$ & 318 & $100 \%$ \\
\hline
\end{tabular}

thors who found positive correlation between hypomineralized changes of teeth and dental caries $[9,10]$. In agreement with our results, the study conducted in Spain in 2014, also reported higher values of DMFT in children with MIH (0.513) in comparison to children without MIH (0.273) [11]. Muratbegović et al. in their study about oral health indices and hypomineralization of first permanent molars and incisors in 12-year-olds reported higher caries prevalence associated with hypomineralization changes [12]. Jeremias et al. in their study about the association between caries and MIH also demonstrated larger DMFT index in children with hypomineralization changes (0.89 $\pm 1.18)$ in comparison to children without hypomineralized changes $(0.43 \pm 1.01)$ [13].

These results are on the other hand in contrast to a recent study of Heitmüller et al. where the association between dental caries and MIH in children aged 10 years was not found. However, the authors did not consider atypical restorations (due to hypomineralized changes) as restorations associated to caries and as such were not part of DMFT, which probably resulted in such finding [14].

The present study found statistically significant correlation between $\mathrm{dmft}(5.80 \pm 3.48)$ and hypomineralized changes. This is not consistent with the majority of scientific research, where higher caries experience in permanent teeth with hypomineralized changes was found, but not in primary teeth $[5,13]$.

Further analysis showed that $80 \%$ of our respondents with hypomineralized changes had at least one DMFT, compared to $50 \%$ in the group of children without $\mathrm{MIH}$, which clearly implicate increased tendency for caries development in teeth with hypomineralization changes. A study conducted in India in 2015, by Tadikonde et al. demonstrated positive correlation between dental caries and $\mathrm{MIH}$, where the prevalence of caries was $27 \%$ in children with MIH [15].

In the present study, mean DMFT/dmft in children with hypomineralized teeth was 2.3 , which was statistically significant compared to the group of children without hypomineralization (1.2). Keeping in mind that the study included eight years old children who had small number of permanent teeth recently erupted, this result can be considered very high. This is in accordance with other studies $[10,16]$. Kirthiga et al. in their study found that the mean DMFT value in respondents affected with MIH was 3.2, which was significantly higher than the mean DMFT value of controls (0.8) [17].

MIH is associated with structural weakness and tooth hypersensitivity; therefore, there is high chance for performing poor oral hygiene and subsequently more chance for dental caries development. Histological examinations of hypomineralized teeth showed that oral bacteria can get embedded deeper into dentin of affected teeth, which obviously increase risk for dental caries [18].

Since dental treatment of MIH can pose a lot of difficulties, in our study the need for dental treatment of teeth affected by hypomineralized changes was estimated. It was determined that more than $70 \%$ of teeth with hypomineralized changes did not require treatment. This result can be interpreted as moderate and in accordance with similar results of other authors $[19,20]$. The study conducted in Spain in 2014 recognized the need for treatment in eight-year-old children with MIH in accordance with WHO criteria classifying them as examinations, urgent treatment and necessary treatment-but not urgent. They found that $3.8 \%$ of children with MIH required urgent treatment because of the severity of defects, while $27.9 \%$ required some type of treatment that was not an emergency [11].

\section{CONCLUSION}

Significant association between MIH and caries was found in the current study. Dental caries was more common in hypomineralized teeth, thus playing role in further deterioration of affected teeth. This finding implicates need for increased awareness in regards to hypomineralization, early dental treatment and adequate prevention.

\section{REFERENCES}

1. Dietrich G, Sperling S, Hetzer G. Molar incisor hypomineralisation in a group of children and adolescents livin in Dresden (Germany). Eur J Paediatr Dent. 2003; 4(3):133-7. [PMID: 14529334]

2. Weerheijm KL. Molar Incisor Hypomineralisation (MIH). Eur J Paediatr Dent. 2003; 4(3):114-20. [PMID: 14529330]

3. Weerheijm KL, Duggal M, Mejare J, Papagiannoulis L, Koch G, Martens LC, et al. Judgement criteria for molar incisor Hypomineralisation $(\mathrm{MIH})$ in Epidemiologic studies. A summary of the European meeting on MIH held in Athens, 2003. Eur J Paediatr Dent. 2003; 4(3):110-3. [PMID: 14529329]

4. Kilpatrick N. New developments in understanding development defects of enamel: optimizing clinical outcomes. J Orthod. 2009; 36(4):277-82. [DOl: 10.1179/14653120723310] [PMID: 19934246]

5. Grošelj $M$, Jan J. Molar incisor hypomineralization and dental caries among children in Slovenia. Eur J Paediatr Dent. 2013; 14(3):241-5. [PMID: 24295012]

6. Jälevik B, Klingberg G. Treatment outcomes and dental anxiety in 18-year-olds with $\mathrm{MIH}$, comparisons with healthy controls - a longitudinal study. Int J Paed Dent. 2012; 22:85-91. [DOI: 10.1111/j.1365-263X.2011.01161.x]

7. Onat H, Tosun G. Molar incisor hypomineralization.) Pediatr Dent. 2013; 1(3):53-7 [DOI: 10.4103/WKMP-0028.121202]

8. World Health Organization. Oral health surveys. Basic methods. 4th ed. Geneva: WHO; 1997. p. 39-46. 
9. da Costa Silva CM, Jeremias F, de Souza JF, Cordeiro Rde C, Santos-Pinto L, Zuanon AC, et al. Molar incisor hypomineralization: prevalence, severity and clinical consequences in Brazilian children. Int J Paediatr. 2010; 20(6):426-34. [DOI: 10.1111/j.1365263X.2010.01087.x] [PMID: 20738434]

10. Cho SY, Ki Y, Chu V. Molar incisor hypomineralization in Hong Kong Chinese children. Int J Paediatr Dent. 2008; 18(5):348-52. [DOI: 10.1111/j.1365-263X.2008.00927.x] [PMID: 18637048]

11. Garcia-Margarit M, Catalá-Pizarro M, Montiel-Company JM, Almerich-Silla JM. Epidemiologic study of molar-incisor hypomineralization in 8-year-old Spanish children. Int J Paediatr Dent. 2014; 24(1):14-22. [DOl: 10.1111/ipd.12020] [PMID: 23317396]

12. Muratbegović A, Marković N, Kobašlija S, Zukanović A. Indeksi oralnog zdravlja i hipomineralizacija kutnjaka i sjekutića kod bosanske djece u dobi od 12 godina. Acta Stomatol Croat. 2008; 42(2):155-63. [PMID: 18076849]

13. Jeremias F, de Souza JF, Silva CM, Cordeiro Rde C, Zuanon AC, Santos-Pinto L. Dental caries experience and Molar-Incisor Hypomineralization. Acta Odontol Scand. 2013; 71(3-4):870-6. [DOI: 10.3109/00016357.2012.734412] [PMID: 23351220]

14. Heitmüller D, Thiering E, Hoffmann U, Heinrich J, Manton D, Kühnisch J, et al. Is there a positive relationship between molar incisor hypomineralisations and the presence of dental caries? Int J Paediatr Dent. 2012; 2:1-9. [DOl: 10.1111/j.1365263X.2012.01233.x]
15. Tadikonda AN, Acharya S, Pentapati KC. Prevalence of Molar Incisor Hypomineralization and its Relation With Dental Caries in School Children of Udupi District, South India. World J Dent. 2015; 6(3):143-6. [DOI: 10.5005/jp-journals-10015-1330]

16. Preusser SE, Ferring V, Wleklinski C, Wetzel WE. Prevalence and severity of molar-incisor hypomineralization in a region of Germany - a brief communication.J Public Health Dent. 2007; 67(3):148-50. [DOI: 10.1111/j.1752-7325.2007.00040.x] [PMID: 17899899]

17. Kirthiga M, Poornima P, Praveen R, Gayathry P, Manju M, Priya $M$. Prevalence and severity of molar incisor hypomineralization in children aged 11-16 years of a city in Karnataka, Davangere. I Indian Soc Pedod Prev Dent. 2015; 33(3):213-17. [DOI: 10.4103/09704388.160366] [PMID: 26156275]

18. Kemoli AM. Molar incisor hypomineralization (MIH): A possible factor in the high prevalence of dental caries in developing nations. Edorium J dent. 2015; 2:51-5. [DOI: 10.5348/D01-2015-11-ED-9]

19. Kusku OO, Caglar E, Sandalli N. The prevalence and etiology of molar-incisor hypomineralisation in a group of children in Istanbul. Eur J Paediatr Dent. 2008; 9(3):139-44. [PMID: 18844443]

20. Lygidakis NA, Dimou G, Briseniou E. Molar-incisor-hypomineralisation (MIH). Retrospective clinical study in Greek Children. I. Prevalence and defects characteristics. Eur Arch Paediatr Dent. 2008; 9(4):200-6. [PMID: 1905447] 


\title{
Povezanost hipomineralizacije sekutića i kutnjaka sa pojavom karijesa kod osmogodišnjaka
}

\author{
Ljiljana Marković Đurić', Olivera Dolić², Marija Obradović2, Mirjana Tošić3 ${ }^{3}$ Maja Ernaut ${ }^{4}$ \\ IJZU Dom zdravlja, Kneževo, Bosna i Hercegovina; \\ ${ }^{2}$ Univerzitet u Banjoj Luci, Medicinski fakultet, Banja Luka, Bosna i Hercegovina; \\ ${ }_{3}^{3}$ ZZU Dom zdravlja, Gradiška, Bosna i Hercegovina; \\ ${ }^{4}$ IZU Dom zdravlja, Srbac, Bosna i Hercegovina
}

\begin{abstract}
KRATAK SADRŽAJ
Uvod Cilj ovog istraživanja je bio utvrditi odnos između pojave hipomineralizacije sekutića i kutnjaka i karijesa školske dece u regiji Banja Luka, Republika Srpska.

Materijal i metode Epidemiološka studija preseka je sprovedena na teritoriji banjalučke regije i uključivala je 540 dece uzrasta osam godina, kod kojih je registrovano prisustvo $\mathrm{MIH}$-a. Stanje zdravlja zuba ocenjivano je upotrebom sistema KEP.

Rezultati Analiza rezultata prevalencije karijesa je pokazala da je KEP/kep statistički značajno veći u grupi dece s MIH-om u odnosu na grupu dece bez $\mathrm{MIH}-\mathrm{a}(\mathrm{p}<0,001)$. $\mathrm{U}$ ispitivanoj grupi dece utvrđeni su visoke vrednosti ispitivanih parametara prevalencije karijesa, karijes indeks osoba (KIO) i karijes indeks prosek (KIP).

Zaključak Istraživanje pokazuje značajnu povezanost između pojave hipomineralizacije sekutića i kutnjaka i karijesa.

Ključne reči: hipomineralizacija sekutića i kutnjaka; karijes; deca
\end{abstract}

\section{UVOD}

Oralno zdravlje je bitan deo opšteg zdravlja. Bez obzira na poznatu etiologiju, karijes je još uvek najraširenija bolest civilizacije i globalni problem, iako je tokom proteklih decenija u mnogim razvijenim zemljama primećen pad prevalencije ovog oboljenja kod dece i adolescenata. Nasuprot smanjenju kariozne patologije, razvojni poremećaji gleđi sve više skreću pažnju u kliničkoj praksi i kao takvi postaju izraženiji javnozdravstveni problem [1].

Poslednjih nekoliko godina primećena je učestala pojava strukturnih promena u gleđi koje zahvataju prve stalne kutnjake i sekutiće. Radi boljeg razumevanja ovih promena i uticaja na celokupno oralno zdravlje, 2001. godine od strane Karina Werheijma i saradnika predložen je jedinstven termin - Molarnoincizivna hipomineralizacija (MIH), koji je usvojen na sastanku Evropske akademije za dečju stomatologiju održanom u Atini 2003. godine [2]. Definiše se kao hipomineralizacija sistemskog porekla koja zahvata jedan ili više prvih stalnih kutnjaka, često uključujući i stalne sekutiće [3].

Osim kliničkih implikacija MIH-a (preosetljivost zuba na termičke, hemijske i mehaničke nadražaje, estetski nedostaci - kredasta, žućkasta ili braonkasta zatamnjenja), hipomineralizovane promene su bitne kao jaki prediktori karijesa. Povećan rizik za razvoj karijesa kod zuba zahvaćenih hipomineralizovanim promenama posledica je ne samo meke i porozne gleđi već i otežane oralne higijene usled povećane osetljivosti zuba na nadražaje [4]. Faktor koji bi takođe mogao da doprinese većem riziku od karijesa, utvrđen kod dece s MIH promenama, jeste smanjena salivacija i niži pH pljuvačke [5]. Neretko, osetljivost može biti izražena do mere da se teško postiže zadovoljavajuća analgezija prilikom preparacije. Podaci iz literature pokazuju da deca sa ovom vrstom defekata zahtevaju obimnije i često ponovne restaurativne tretmane. Restaurativni tretmani ovih zuba predstavljaju izazov i za pacijenta i za stomatologa. U mnogim slučajevima strah i teskoba kod deteta pogoršavaju i otežavaju tretman $[6,7]$.
Iz navedenih razloga, rane kontrole, praćenje zuba tokom nicanja, donošenje pravovremene i tačne dijagnoze MIH-a su ključ za pravilan odabir terapijskih postupaka i prevenciju daljnjih oštećenja.

Cilj istraživanja je bio utvrditi prevalenciju karijesa kod dece sa MIH-om, te utvrditi postoji li povezanost između pojave hipomineralizovanih promena i karijesa mlečnih i stalnih zuba.

\section{MATERIJAL I METODE}

Epidemiološka studija preseka je sprovedena na teritoriji banjalučke regije i uključivala je 540 dece uzrasta osam godina, kod kojih je registrovano prisustvo MIH-a i stanje zdravlja zuba ocenjeno upotrebom KEP sistema. Istraživanje je sprovedeno između marta 2015. i septembra 2016. godine. Uzrast osam godina odabran je zato što se u datom periodu prvi stalni kutnjaci i sekutići nalaze u ranom posterupcionom periodu, kada je incidencija karijesa niža, čime se smanjuje mogućnost maskiranja hipomineralizacije karioznom lezijom [2]. Istraživanje je obavljeno uz saglasnost Etičkog odbora JZU Zavod za stomatologiju u Banjoj Luci i Etičkog odbora JZU Dom zdravlja Banja Luka. Pre početka istraživanja roditelji su potpisali saglasnost za učešće dece u istraživanju.

Uzorkovanje je sprovedeno kroz dve faze. U prvoj fazi metodom slučajnog izbora od ukupno 30 škola odabrano je devet, a u drugoj fazi metodom stratifikovanog uzorka izabrana su deca iz odabranih škola. Pre početka istraživanja roditelji su potpisali informisani pristanak o saglasnosti za učešće u istraživanju. Deca čiji roditelji nisu dali svoj pismeni pristanak isključena su iz istraživanja, kao i deca sa fiksnim ortodontskim aparatom, koji ometa adekvatan pregled zuba. Pregled dece obavljen je u stomatološkoj stolici, pod veštačkim osvetljenjem, od strane jednog kalibrisanog stomatologa, korišćenjem standardnog stomatološkog ogledalca i sonde. Po potrebi su korišćene pamučne vatice za uklanjanje dentalnog biofilma. MIH je klinički dijagnostikovan na osnovu kriterijuma koje je opisao Weerheijm 
2003. godine: ograničena zamućenja gleđi, posteruptivni prekid gleđi, atipična restauracija, ekstrakcija molara zbog MIH-a, retencija, nenicanje molara i sekutića [3]. Lezije zuba koje su bile manje od $1 \mathrm{~mm}$ nisu uključivane u studiju; opaciteti koji su uočavani samo na sekutićima, bez zahvaćenosti kutnjaka, nisu dijagnostikovani kao MIH. Slučajevi većih karijesnih lezija oivičeni zamućenjima po ivicama kaviteta dijagnostikovani su kao MIH.

Iskustvo karijesa zuba je registrovano na osnovu $\mathrm{KEP} / \mathrm{kep}$ indeksa (K - karijes, E - ekstrakcija, P - plomba) u skladu sa kriterijumima Svetske zdravstvene organizacije (SZO) 8]. Prevalencija karijesa je izražena statističkim koeficijentima: karijes indeks osoba (KIO), karijes indeks prosek (KIP) i pokazateljem strukture karioznih, ekstrahovanih i plombiranih zuba (struktura KEP). Klinički pregled je obuhvatio sve mlečne i stalne zube.

Distribucija zuba sa MIH-om prema potrebi za tretmanom prikazana je u pet grupa: nije potreban tretman, jednopovršinski ispun, dvopovršinski ili višepovršinski ispun, endodontski tretman i ekstrakcija zuba.

Za statističku analizu korišćen je softver IBM SPSS Statistics 21.0. Za upoređivanje razlika u učestalosti posmatranih obeležja prema grupama ispitanika korišten je Pearsonov $\chi^{2}$ test kontigencije i Mann-Whitney $U$ test. Kao statistički značajne uzimane su vrednosti u kojima je $\mathrm{p}<0,05$.

\section{REZULTATI}

Od ukupno 540 dece uključene u istraživanje, devetoro dece nije dobilo pisanu saglasnost od roditelja, dok dvoje dece nije imalo potpuno iznikla sva četiri prva stalna molara, te su isključeni iz istraživanja. Pregledano je ukupno 529 (97,96\%) dece (254 dečaka i 275 devojčica).

Analiza rezultata prevalencije karijesa je pokazala da je KEP/ kep statistički značajno veći u grupi dece s MIH-om u odnosu na grupu dece bez MIH-a ( $<<0,001)$. (Tabela 1$)$

$\mathrm{U}$ ispitivanoj grupi dece utvrđene su visoke vrednosti ispitivanih parametara prevalencije karijesa, karijes indeks osoba (KIO) i karijes indeks prosek (KIP). (Tabela 2)

Rezultati u Tabeli 3. pokazuju analizu podataka potrebe za tretmanom zuba zahvaćenih hipomineralizovanim promenama.

\section{DISKUSIJA}

Naša studija je imala za cilj da utvrdi povezanost između karijesa i MIH-a kod dece školskog uzrasta na teritoriji banjalučke regije, u Republici Srpskoj. Zbog povećane poroznosti strukture zuba i posledično smanjene mehaničke otpornosti, hipomineralizovane promene se smatraju faktorom rizika za karijes, čak i u populacijama sa niskom rasprostranjenošću karijesa.

Rezultati ove studije pokazuju značajnu povezanost između karijes indeksa stalnih zuba $(1,41 \pm 1,62)$ i hipomineralizovanih promena. Ovaj nalaz je u skladu sa istraživanjima većeg broja autora, koji su pronašli pozitivnu korelaciju između hipomineralizovanih promena i karijesa $[9,10]$. U skladu sa našim nalazom, studija sprovedena u Španiji 2014. takođe je ustanovila veće vrednosti KEP-a kod dece s MIH-om $(0,513)$ u odnosu na decu bez MIH-a $(0,273)$ [11]. Studija Muratbegovića i saradni- ka o indeksima oralnog zdravlja i hipomineralizaciji kutnjaka i sekutića kod dece uzrasta 12 godina utvrdila je visoku prosečnu vrednost KEP indeksa - od 4,16 $\pm 2,92$ [12]. U skladu sa rezultatima ove studije, Jeremias i saradnici u svojoj studiji o povezanosti karijesa i MIH-a ustanovili su veći KEP indeks kod dece sa hipomineralizovanim promenama - 0,89 $\pm 1,18 \mathrm{u}$ odnosu na decu bez hipomineralizovanih promena, gde je KEP indeks iznosio 0,43 $\pm 1,01$ [13].

Rezultati ove studije su u kontrastu sa nedavnom studijom Heitmüllera i saradnika, koja nije ustanovila vezu između karijesa i MIH-a kod dece uzrasta 10 godina; međutim, autori u ovoj studiji atipične restauracije nastale kao posledica hipomineralizovanih promena gleđi nisu tretirali kao restauracije koje su povezane sa karijesom i kao takve nisu bile deo KEP indeksa, što je verovatno uticalo na takav rezultat [14].

U ovoj studiji je utvrđena statistički značajna korelacija između hipomineralizovanih promena i KEP-a $(5,80 \pm 3,48)$. Ovaj nalaz je u suprotnosti sa izveštajima većine autora koji su utvrdili veću rasprostranjenost karijesa kod stalnih zuba dece sa hipomineralizovanim promenama, ali ne i kod mlečnih zuba $[5,13]$.

Analiza rezultata je pokazala da $80 \%$ dece sa hipomineralizovanim promenama ima bar jedan KEP, u odnosu na 50\% u grupi dece bez MIH-a, što upućuje na povećanu sklonost ka razvoju karijesa kod zuba sa hipomineralizacijom. Studija sprovedena u Indiji 2015. godine, od strane Tadikonde i saradnika, ustanovila je pozitivnu korelaciju između karijesa i MIH-a, pri čemu je prevalenca karijesa iznosila 27\% kod dece s MIH-om [15].

KIP u ovoj studiji iznosi 2,3, što je statistički značajno u odnosu na grupu dece bez hipomineralizovanih promena $(1,2)$. S obzirom na to da su u studiji zastupljena deca uzrasta osam godina, koja imaju manji broj izniklih stalnih zuba, ovaj podatak je dosta ozbiljan. Ovakav rezultat je u skladu s nalazima drugih istraživanja [10, 16]. Istraživanje Kirthige i saradnika u Indiji, 2015. godine, ustanovilo je KIP 3,2 kod dece sa MIH-om, što je znatno više od KIP vrednosti u kontrolnoj grupi $(0,8)$ [17].

Ovakvi rezultati su očekivani s obzirom na to da je MIH povezan sa oslabljenom strukturom zuba i hipersenzitivnošću. Deca s MIH-om neće moći da održavaju dobru oralnu higijenu, te će se zbog toga i razviti karijes. Histološka ispitivanja hipomineralizovanih zuba su pokazala da oralne bakterije mogu biti ugrađene duboko u dentin zahvaćenih zuba, te postoji očigledna mogućnost za povećan rizik od karijesa na zubima zahvaćenim tim promenama [18].

Imajući u vidu poteškoće koje se javljaju u lečenju dece sa hipomineralizovanim promenama, u studiji je urađena i procena potrebe za stomatološkim tretmanom na zubima zahvaćenim hipomineralizovanim promenama. U ovom istraživanju je utvrđeno da kod više od 70\% zuba sa hipomineralizovanim promenama nije potreban tretman. Ovaj nalaz se može tumačiti kao umeren, u skladu sa sličnim rezultatima drugih studija $[19,20]$. Studija sprovedena u Španiji 2014. godine istraživala je potrebu za tretmanom kod dece osmogodišnjeg uzrasta sa hipomineralizovanim promenamana kutnjaka i sekutića, u skladu s preporukama SZO, klasifikujući ih na preglede, hitan tretman i neophodan tretman, ali koji nije hitan. Ustanovili su da je kod 3,8\% dece sa MIH-om potreban hitan tretman zbog teških defekata, dok je kod 27,9\% potrebna neka vrsta lečenja koja nije hitna [11]. 


\section{ZAKLJUČAK}

Istraživanje je pokazalo da postoji visoka prevalencija karijesa kod dece sa MIH-om, kao i značajna povezanost između MIH-a i karijesa. Veća učestalost karijesa na hipomineralizovanim zu- bima upućuje na to da kariozno oboljenje igra značajnu ulogu u pogoršanju zdravstvenog stanja zuba zahvaćenih hipomineralizovanim promenama, te da postoji potreba za podizanjem svesti o molarno-incizivnoj hipomineralizaciji, pravovremenom tretmanu i prevenciji karijesa. 